\title{
Retardation of plastic instability via damage-enabled microstrain delocalization
}

\author{
J. P. M. Hoefnagels ${ }^{1}$ C. C. Tasan ${ }^{2}$ F. Maresca ${ }^{1,3} \cdot$ F. J. Peters ${ }^{1}$. \\ V. G. Kouznetsova ${ }^{1}$
}

Received: 23 April 2015/Accepted: 6 June 2015/Published online: 29 July 2015

(c) The Author(s) 2015. This article is published with open access at Springerlink.com

\begin{abstract}
Multi-phase microstructures with high mechanical contrast phases are prone to microscopic damage mechanisms. For ferrite-martensite dual-phase steel, for example, damage mechanisms such as martensite cracking or martensite-ferrite decohesion are activated with deformation, and discussed often in literature in relation to their detrimental role in triggering early failure in specific dualphase steel grades. However, both the micromechanical processes involved and their direct influence on the macroscopic behavior are quite complex, and a deeper understanding thereof requires systematic analyses. To this end, an experimental-theoretical approach is employed here, focusing on three model dual-phase steel microstructures each deformed in three different strain paths. The micromechanical role of the observed damage mechanisms is investigated in detail by in-situ scanning electron microscopy tests, quantitative damage analyses, and finite element simulations. The comparative analysis reveals the unforeseen conclusion that damage nucleation may have a beneficial mechanical effect in ideally designed dual-phase steel microstructures (with effective crack-arrest mechanisms) through microscopic strain delocalization.
\end{abstract}

J. P. M. Hoefnagels

j.p.m.hoefnagels@tue.nl

1 Department of Mechanical Engineering, Eindhoven University of Technology (TU/e), P.O.Box 513, 5600MB Eindhoven, The Netherlands

2 Max-Planck-Institut fur Eisenforschung, P.O.Box 140444, 40074 Dusseldorf, Germany

3 Materials Innovation Institute (M2i), P.O.Box 5008, 2600GA Delft, The Netherlands

\section{Introduction}

In the last decades, novel advanced high-strength steels (AHSS) with more and more complex microstructures have been introduced (e.g., twinning-assisted plasticity steels [1, 2], quench and partition steels [3, 4], and carbide-free bainite steels $[5,6])$ to achieve superior mechanical performance compared to existing grades. Yet, the connection between the microstructure and the overall mechanical behavior is still not fully set even for the more established AHSS grades, such as dual-phase (DP) steels that have been present for decades [7]. The martensitic-ferritic microstructures of DP steels provide excellent combinations of high strength and good ductility [7-9] at low cost (i.e., low alloying content) and relatively simple thermomechanical processing (i.e., intercritical annealing). Thus, DP steels are nowadays being used or considered for different automotive components, e.g., for crash box structures.

The development of DP steels was triggered in the early 1970s and intensive research has been done since then. A huge experimental literature exists, which has shown the influence of martensite volume fraction $[10,11]$, grain size of the constituents, and grain refinement $[9,12,13]$, as well as carbon content [14], on the ultimate strength and ductility of DP steels. Models that account for such effects have been proposed and widely used, e.g., [15-17].The influence of the morphology of the constituents has also been extensively studied, both from experimental and computational points of view, e.g., [18-20].

A wider application of DP steels is hampered by the limited understanding regarding their failure mechanisms. For example, it is beneficial for weight reduction purposes to employ higher strength DP grades in automotive bodyin-white structures, as it would allow sheet thickness to be 
reduced. However, in such higher strength grades (with higher martensite content), activity of microstructural damage mechanisms may often lead to unpredicted failures during forming operations or upon crash [21, 22]. The limited understanding of the macroscopic fracture processes in DP steel arises from the presence of multiple microstructural damage mechanisms that exhibit complex interactions [23-32]. As a consequence, the applicability of state-of-the-art damage models that aim at modeling multiple, interacting, damage nucleation mechanisms, e.g., [33, 34], is limited by the possibilities for experimental characterization, see e.g., [29, 31].

The challenge is thus clear: developing optimized martensite-ferrite microstructures that enable higher strengths in DP steels, while preserving good toughness. To this end, a vast variety of microstructure variations can be introduced in DP steels by small changes in the composition and/or thermomechanical processing [18, 35-42]. To guide this microstructure design process, micromechanicsbased foundations and design guidelines are needed that would ensure damage-prone microstructures. This research aims to provide an improved understanding in this direction.

There are many investigations in the literature on damage and failure mechanisms in DP steels [23-27, 29]. These reports reveal three general observations:

- Aside from the rarely seen damage incidents at ferrite grain boundaries $\left(D_{\mathrm{FGB}}\right)$, ferrite grain interiors $\left(D_{\mathrm{FGI}}\right)$, or around inclusions $\left(D_{\mathrm{INC}}\right)$, two main damage mechanisms are dominant in DP steel microstructures: martensite cracking $\left(D_{\mathrm{MC}}\right)$ and martensite-ferrite interface damage $\left(D_{\mathrm{MFI}}\right){ }^{1}$

- The relative activity of these two mechanisms, their activation regimes, and their role on the overall mechanical response are strongly microstructure and strain path dependent.

- While its mechanical effect is critical, the overall damage fraction is difficult to detect as it is in the order of few percent even at high deformation levels.

Given these points, it is clear that generic microstructure design guidelines cannot be provided through qualitative analysis of a single microstructure deformed in a single strain path, as is done in most previous works. Therefore, in this research, we aim to improve on this by employing an experimental-numerical approach that has various novelties: (i) Experiments focus on quantitative characterization of ductile damage evolution up to failure, at different strain paths and strain levels; (ii) For these experiments, a recently designed miniaturized Marciniak

\footnotetext{
${ }^{1}$ Note that the latter is often referred to in the literature as martensite-ferrite decohesion mechanism.
}

setup [43] and a novel image post-processing methodology are employed for statistically sound quantification of damage evolution; (iii) Different model DP microstructures (with variation in only a single microstructural variable at a time) are investigated using these techniques; and (iv) For a deeper understanding of the most relevant damage nucleation mechanisms, follow-up in-situ scanning electron microscope (SEM) deformation experiments and finite element simulations are also carried out.

In what follows, first the employed methodology is introduced in detail. The results are presented, starting with the identification of active damage mechanisms and quantification of their activity, followed by focusing on the factors determining the relative activity of the damage mechanisms through a discussion of the numerical results and in-situ damage nucleation images. The report is finalized with the conclusions.

\section{Methodology}

\section{Materials}

To investigate systematically the influence of ferrite grain size and martensite volume fraction, different DP model microstructures are produced where a single microstructural parameter is changed at a time. These microstructures, referred in the text as fine-grained $\left(\mu_{\mathrm{FG}}\right)$, coarse-grained $\left(\mu_{\mathrm{CG}}\right)$, and high martensite $\left(\mu_{\mathrm{HM}}\right)$ microstructures, are designed by thermal processing of non-commercial DP600 and DP800 steel grades of $1 \mathrm{~mm}$ thickness from Tata steel IJmuiden (Fig. 1). These base steels are chosen specifically, as they have almost equal (typical) concentrations of $\mathrm{Mn}, \mathrm{Si}$, and $\mathrm{Cr}$, while differing only in $\mathrm{C}(0.092$ vs. $0.147 \mathrm{wt} \%$, respectively). The $\mu_{\mathrm{CG}}$ is produced by reaustenization of DP600 alloy at $960{ }^{\circ} \mathrm{C}$ for $10 \mathrm{~min}$, followed by air cooling to room temperature, then intercritical annealing at $775^{\circ} \mathrm{C}$ for $30 \mathrm{~min}$, and finally quenching to room temperature. To produce the $\mu_{\mathrm{FG}}$, the re-austenization duration of the same alloy is decreased to $1 \mathrm{~min},{ }^{2}$, keeping the other conditions of the treatment identical. Decrease in austenization duration limits the growth of austenite grains but identical intercritical annealing treatment ensures largely unaffected martensite volume fraction $(\sim 33 \%)$ and morphology. To produce the $\mu_{\mathrm{HM}}$ microstructure, DP800 steel is heat treated in the same manner as the $\mu_{\mathrm{CG}}$. For the same intercritical annealing temperature, the DP800 steel with higher carbon content produces a higher martensite volume percentage ( $\sim 1 \%$ ) compared to the DP600 steel

\footnotetext{
${ }^{2}$ Note that accompanying dilatometry experiments reveals that the austenite transformation is completed within this duration.
} 

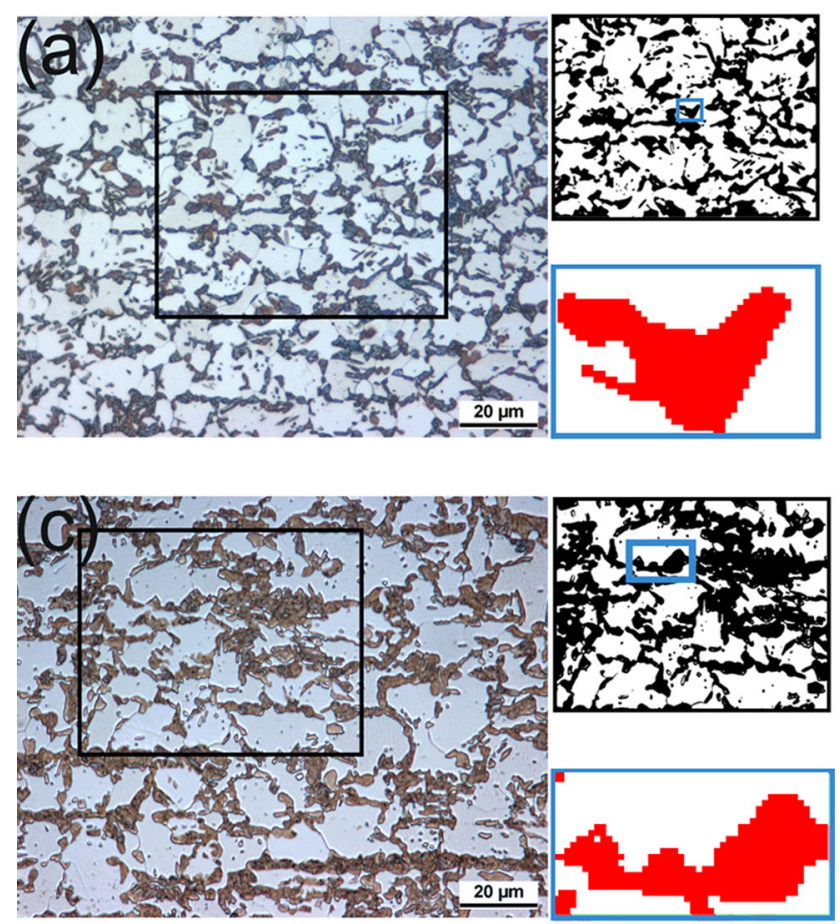

Fig. 1 Optical microscopy images and SEM images (not shown) of a the $\mu_{\mathrm{FG}}$, b the $\mu_{\mathrm{CG}}$, and $\mathbf{c}$ the $\mu_{\mathrm{HM}}$ microstructures, recorded at the center cross section (sheet thickness in vertical direction) of the specimen; no dependence of the generated microstructures on the prior sheet rolling direction was observed. Each optical image ac was first converted into black (martensite) and white (ferrite) images (top right subfigure of $\mathbf{a}-\mathbf{c}$ ), and then converted to a representative volume element (RVE) for FEM analysis (each SEM pixel is converted to a finite element to a total of $\sim 1000 \times 800$ elements), of

with lower carbon content, while the martensite carbon contents in both are, on average, identical (Fig. 1).

\section{Deformation experiments}

Each of the three above-mentioned DP microstructures is deformed to fracture in three different strain paths: uniaxial tension (UAT), plane strain tension (PST), and biaxial tension (BAT). To carry out these deformation experiments, the miniaturized Marciniak setup with a punch diameter of $40 \mathrm{~mm}$ [43], shown in Fig. 2a, is employed. A finite element analysis of this Marciniak test showed that the stress in the thickness direction is negligible and that indeed a UAT, PST, or BAT stress state is achieved [43]. Figure $2 b-d$ shows digital image correlation (DIC) overlays of the von Mises strain fields measured in situ under optical microscopy, obtained in the three considered strain paths. Aramis software (GOM Gmbh.) is employed for the DIC analysis. These samples are further characterized for the quantitative damage analysis which is described next. Furthermore, for a detailed analysis of the damage
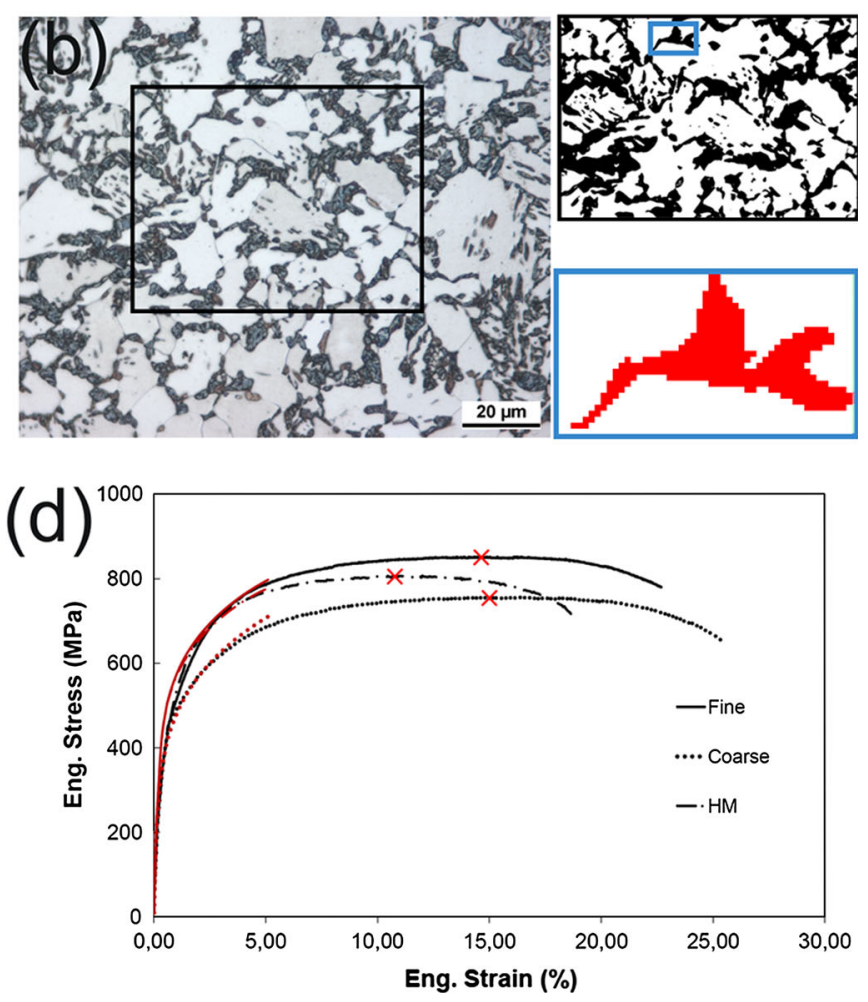

which a zoom with martensite colored red (bottom right subfigure of $\mathbf{a}-\mathbf{c})$ shows the fine mesh used. Shown in $\mathbf{d}$ are the global stress-strain curves under uniaxial tension of the $\mu_{\mathrm{FG}}, \mu_{\mathrm{CG}}$, and $\mu_{\mathrm{HM}}$ microstructures, with the point of plastic instability marked with a red cross. In dark red are shown the simulated stress-strain curves for each microstructure, which were fitted to the experimental curves by adapting the plastic model parameters (given in Table 1) (Color figure online)

nucleation and growth mechanisms, in-situ scanning electron microscope deformation experiments are carried out in an FEI Quanta 600F microscope.

\section{Quantitative damage analysis}

For a systematic quantitative analysis of the deformationinduced evolution of the damage mechanisms, a semi-automatic Statistical Damage Identification program is developed (in MATLAB) and employed in this study. Within this methodology, five cross sections representing five different strain levels (measured using DIC) are metallographically prepared in each sample that is deformed to fracture. Per each strain level, five images are taken at an optimized magnification of $456 \times$ that ensures a large (i.e., representative) field-of-view and sufficient resolution. Following inter-image contrast/brightness homogenization, each image is analyzed in the gray value thresholdingbased image analysis algorithm (Fig. 3). Each detected damage incident is also confirmed by the operator, and classified regarding the mechanism. Note that the damage 

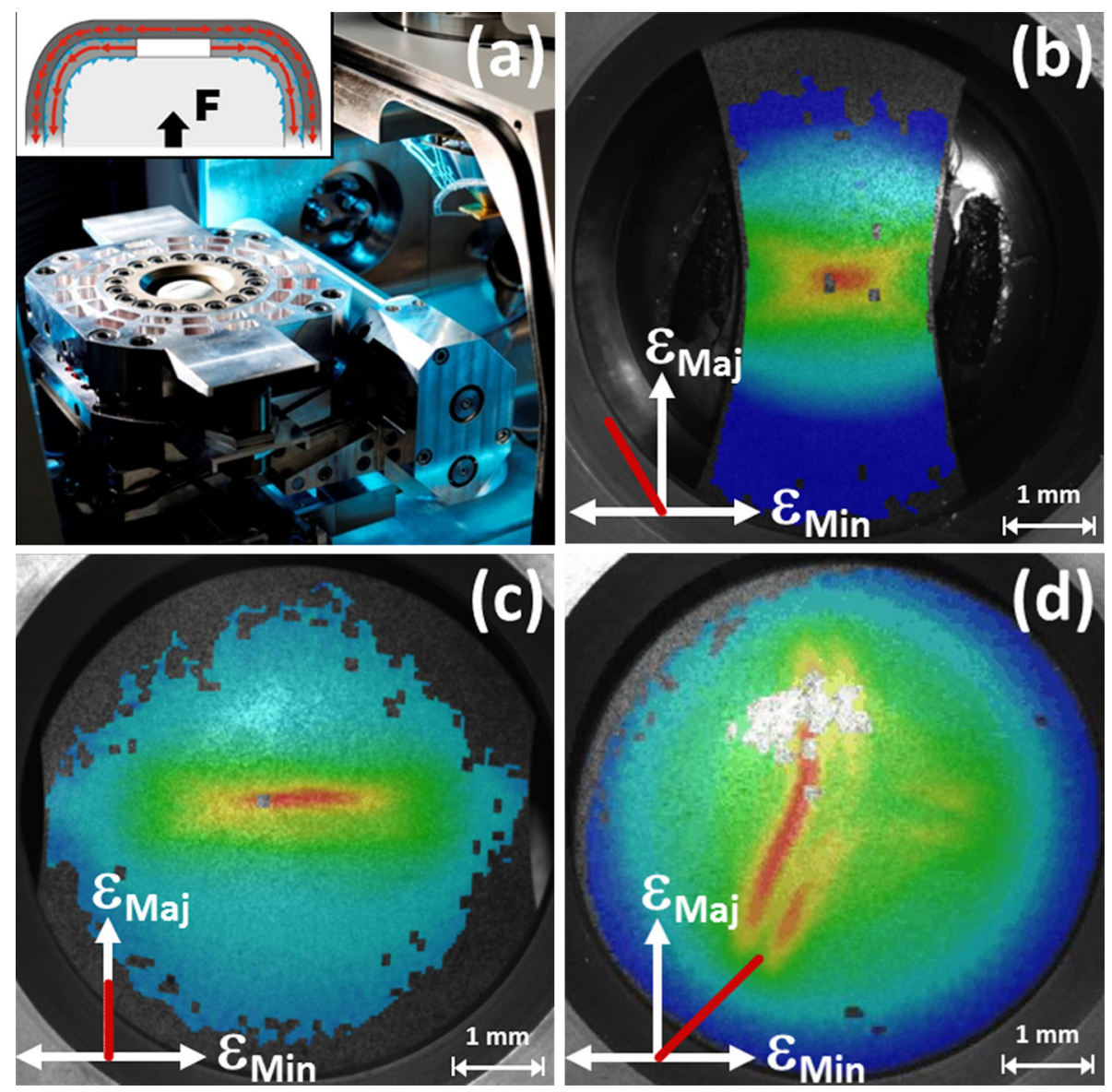

Fig. 2 a Photograph of the miniaturized Marciniak setup [43], mounted in the door of the SEM, and used to perform all deformation experiments. The inset shows a schematic representation of the working principle of a Marciniak test on a specimen and so-called 'washer' (with central hole), where the red arrows show the in-plane displacement and the blue arrows the friction direction [43]. b-d The Real-time recorded optical images of the DP steel with fine-grained microstructure loaded under b UAT, $\mathbf{c}$ PST, and d BAT up to the first point of failure, and overlaid with the von Mises strain field obtained

incident density, i.e., the number of damage sites per area, is recorded instead of the more commonly used damage area fraction in order to reduce the otherwise large influence of a few large damage sites on the damage statistics. Note also that during the calculation of the damage incident density for a given strain level, a correction is applied to take into account the change in reference area due to the evolving in-plane strain and cross contraction along the thickness direction.

\section{Modeling methodology}

Optical microscopy images from $\mu_{\mathrm{FG}}, \mu_{\mathrm{CG}}$, and $\mu_{\mathrm{HM}}$ specimens are binarized in MATLAB for clear classification of the martensite and ferrite regions. A 2D finite element mesh with bilinear square finite elements is generated through digital image correlation. For each of the 3 strain paths, the strain fields have been used to calculate the evolution of the major strain, $\varepsilon_{\text {Maj }}$, as a function of the minor strain, $\varepsilon_{\text {Min }}$, which is shown in the inserts by the red curves. Note that at these critical strains the correlation of some subsets was lost due to large out-of-plane rotations at the specimen edge and detachment of the spray paint pattern at the specimen center, however, this did not interfere with the analysis (Color figure online)

on a representative portion of the image, such that the global martensite volume fraction is preserved. Periodic boundary conditions are applied to all representative volume elements (RVE).

The elastic phase parameters are adopted from [44], i.e., a Young's modulus of 220 and $195 \mathrm{GPa}$ for ferrite and martensite, respectively, and a Poisson's ratio of 0.3 for both phases. For each phase, the plastic deformation is modeled with a Ludwik-type stress-strain relationship $\left(\sigma=\sigma_{y}+K \varepsilon_{p}^{n}\right)$. Note that the effect of the crystal lattice misorientation of neighboring ferrite grains is not considered in such models. The Ludwik's model parameters, which are given in Table 1, were fitted on the experimental data of Fig. 1d, where it is shown that a reasonable fit is achieved in the regime where the simulations are used in 
Fig. 3 Screen capture of the semi-automatic statistical damage identification algorithm, which automatically identifies all damage incident areas and sequentially prompts each damage incident for classification by the user (through a pop-up selection box, not shown here). To assist in the assessment of the type of damage incident, the damage site is simultaneously shown at low, intermediate, and high magnification (respectively, background, top-left, and bottom-left image) and at high magnification with rainbow color map (bottom right image) (Color figure online)

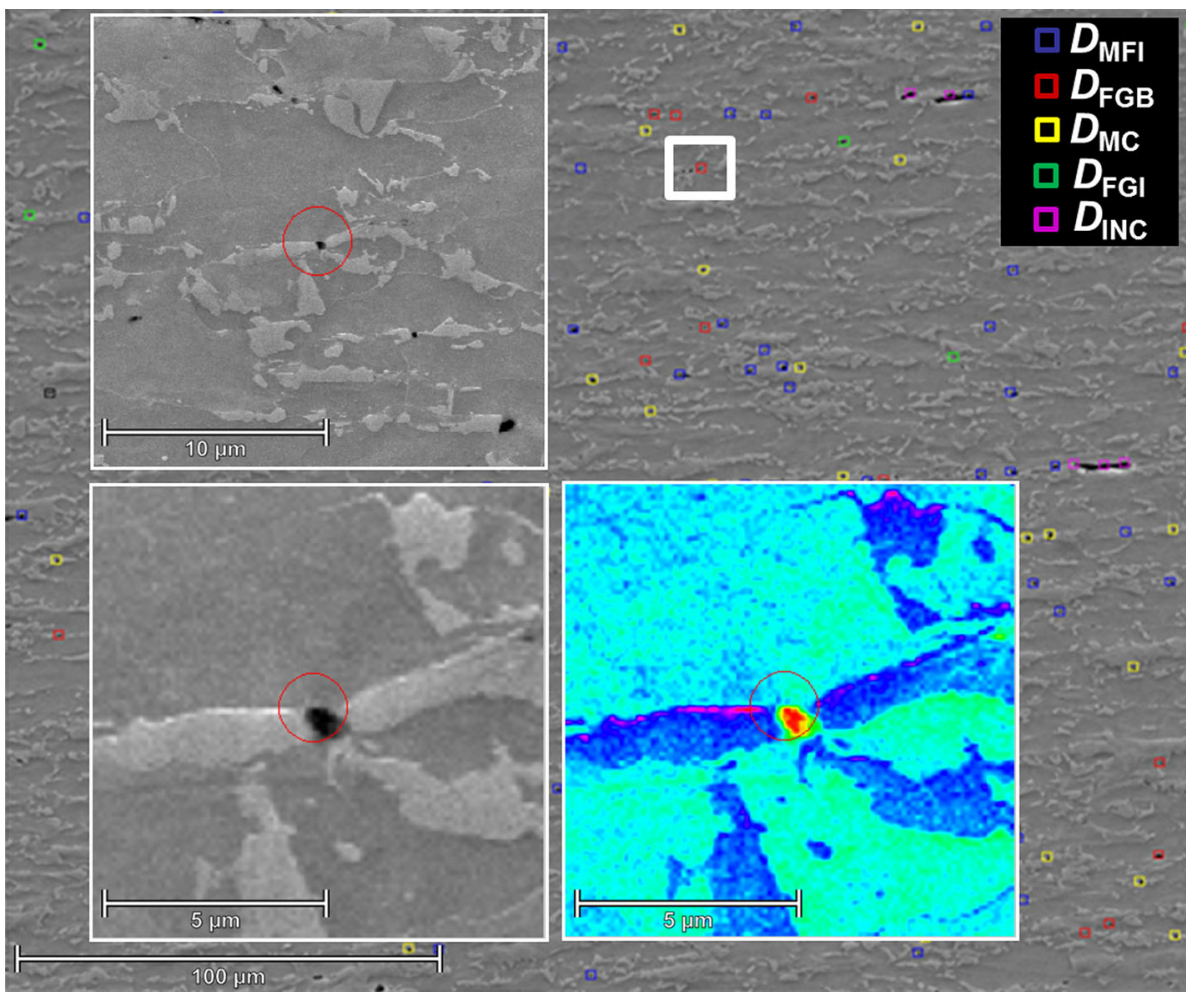

Table 1 Model parameters of the Ludwik's yield strength for each phase and microstructure, as fitted to the data of Fig. 1d

\begin{tabular}{llll}
\hline Microstructures & $\begin{array}{l}\text { Yield } \\
\text { strength } \\
(\mathrm{MPa})\end{array}$ & $\begin{array}{l}\text { Hardening } \\
\text { coefficient } \\
(\mathrm{MPa})\end{array}$ & $\begin{array}{l}\text { Ludwik } \\
\text { coefficient }\end{array}$ \\
\hline Fine $\left(\mu_{\mathrm{FG}}\right)$ & & & \\
$\quad$ Ferrite & 220 & 1300 & 0.33 \\
$\quad$ Martensite & 800 & 6000 & 0.70 \\
Coarse $\left(\mu_{\mathrm{CG}}\right)$ & & & \\
Ferrite & 200 & 1450 & 0.43 \\
$\quad$ Martensite & 800 & 5000 & 0.70 \\
High martensite $\left(\mu_{\mathrm{HM}}\right)$ & & & 0.32 \\
Ferrite & 180 & 1150 & 0.60 \\
Martensite & 650 & 4300 & \\
\hline
\end{tabular}

this work (below $5 \%$ major strain). Interestingly, the ferrite yield strength increases from $\mu_{\mathrm{CG}}$ to $\mu_{\mathrm{FG}}$, as expected from the Hall-Petch effect, and the martensite yield strength for the $\mu_{\mathrm{HM}}$ is lower as might be expected from the larger martensite island size.

A commercial finite element software package (MSC Marc) is used to perform the simulations. For each microstructure $\left(\mu_{\mathrm{FG}}, \mu_{\mathrm{CG}}\right.$, and $\left.\mu_{\mathrm{HM}}\right)$, three strain paths UAT, PST, and BAT are considered. The UAT is simulated by employing plane stress finite elements (free out-of-plane contraction) and by assigning displacement along the rolling direction, while keeping the other directions free. The PST condition is simulated employing plane strain finite elements (fixed thickness), by assigning displacement along the rolling direction and free transverse displacement. Finally, the BAT condition is simulated using generalized plane strain finite elements, which allow prescription of constant thickness change together with the usual displacement along the rolling direction (transverse direction is free to contract).

\section{Results and discussion}

\section{Variation of strain path}

\section{Quantitative damage analysis}

As a first step toward the goal of statistically relevant characterization of ductile damage evolution up to failure, all possible damage mechanisms in the three DP microstructures $\left(\mu_{\mathrm{FG}}, \mu_{\mathrm{CG}}\right.$, and $\left.\mu_{\mathrm{HM}}\right)$ and three strain paths (UAT, PST, and BAT) were extensively studied by exploiting the in-situ SEM capabilities of the miniaturized Marciniak setup. The five most relevant damage mechanisms are presented in Fig. 4. These five mechanisms, which are also the dominant mechanisms observed in the literature [23-27, 29], were chosen as categories in the 
Fig. 4 The most relevant damage mechanisms encountered in the DP microstructures, as observed with in-situ scanning electron microscopy: a Martensite cracking (MC), b, c MartensiteFerrite Interface damage (MFI), d damage at a ferrite grain boundary (FGB), e damage at the ferrite grain interior (FGI), and $\mathbf{f}$ damage around an INClusion (INC). For all images, except image (c), the scale bar indicates a length of $1 \mu \mathrm{m}$. The ' $M$ ' and ' $F$ ' symbols and solid and dashed guidelines denote, respectively, martensite, ferrite, a martensite-ferrite interface, and a ferrite-ferrite grain boundary, which have been identified by careful investigation at the highest magnification level
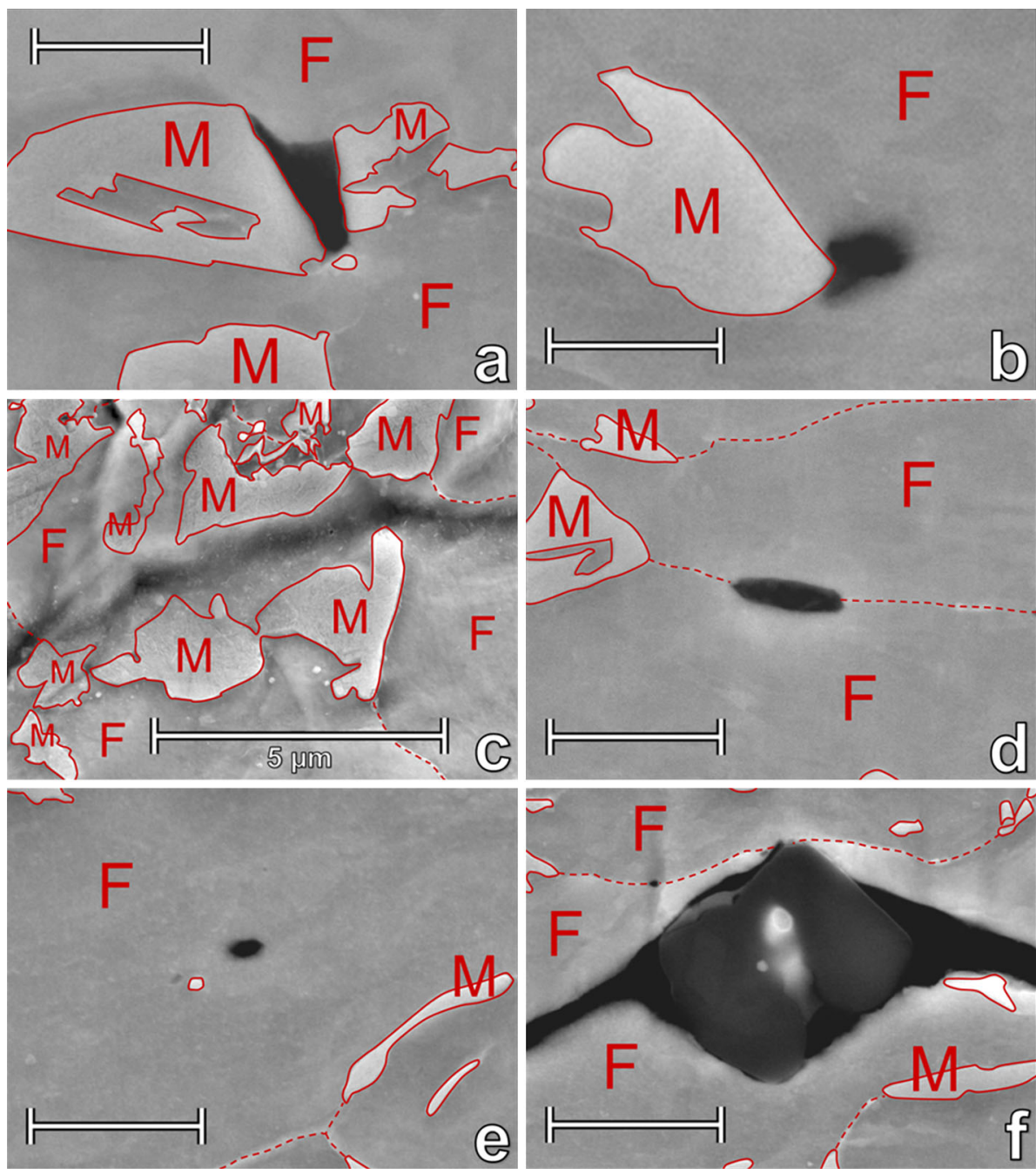

semi-automatic statistical damage identification algorithm (Fig. 3) as a starting point for the quantitative damage analysis, discussed next.

The analysis starts with the fine-grained $\left(\mu_{\mathrm{FG}}\right)$ microstructure, for which the different damage mechanisms were quantified for the three loading states (UAT, PST, and BAT). The damage incident densities of the five different damage mechanisms $\left(D_{\mathrm{MC}}, D_{\mathrm{MFI}}, D_{\mathrm{FGB}}, D_{\mathrm{FGI}}\right.$, and $D_{\text {INC }}$ ) are shown in Fig. 5 as function of the von Mises strain, with the vertical dashed lines denoting the strain level at the point of necking (i.e., global localization). Each data point was obtained by quantifying all damage incidents over five large-area $\left(300 \times 300 \mu \mathrm{m}^{2}\right)$ SEM images, i.e., a total area of $450,000 \mu \mathrm{m}^{2}$. This large amount of data allows for a very accurate determination of the averaged damage incident density. It should be noted, however, that the damage incident density inherently shows large variability due to the strong heterogeneity of the DP microstructure even in commercial grades, as can be observed by the wide error bands in Fig. 5. Perhaps this inherent variability may also explain why, to our knowledge, such an extensive quantification of the relevant damage mechanisms as a function of strain level and for different strain paths and microstructures has not been carried out before.

The first aspect to note from Fig. 5 is that $D_{\mathrm{FGB}}, D_{\mathrm{FGI}}$, and $D_{\text {INC }}$ damage incidents are all clearly present, however, only to a limited extent; therefore, these mechanisms most probably do not play a critical role in controlling the necking and failure behavior. For this reason, the investigation will focus on the $D_{\mathrm{MFI}}$ and $D_{\mathrm{MC}}$ damage mechanisms, for which a number of interesting observations can be made as follows:

(1) $D_{\mathrm{MFI}}$ is the dominant damage mechanism and its incident density increases from UAT to PST to BAT, whereas $D_{\mathrm{MC}}$ is negligible at UAT, increases slightly at PST, but becomes important for BAT. 

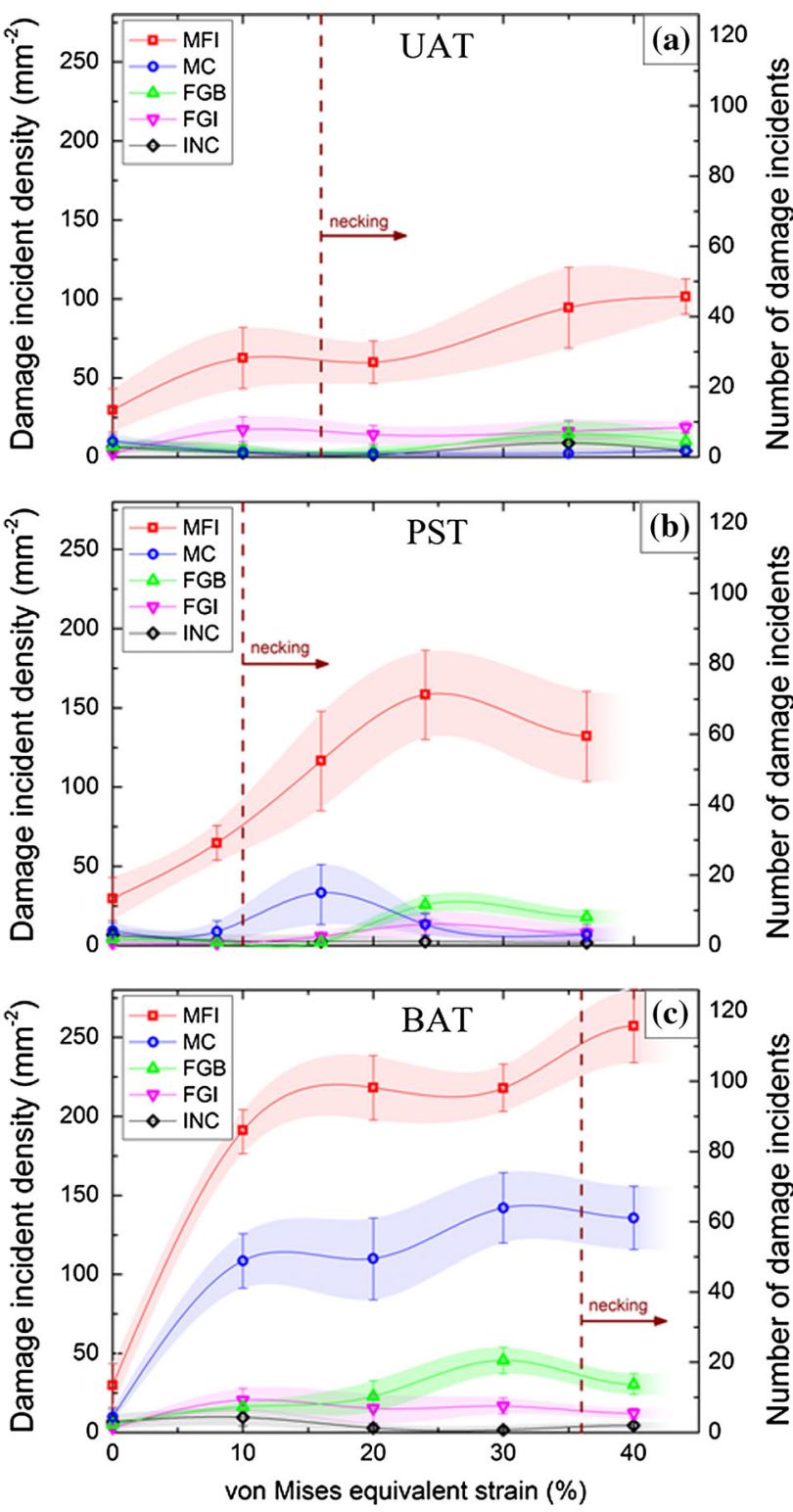

Fig. 5 Damage incident areal density versus von Mises equivalent strain, measured using the damage quantification methodology for the fine-grained microstructure $\left(\mu_{\mathrm{FG}}\right)$ loaded under a uniaxial tension (UAT), $\mathbf{b}$ plane strain tension (PST), and $\mathbf{c}$ biaxial tension (BAT). For each strain level, 5 large-view SEM scans were analyzed for a total area of $450,000 \mu \mathrm{m}^{2}$. Data points and error bars represent, respectively, average values and their standard deviation of the five different damage mechanisms that are explained in Fig. 4. Dashed vertical lines denote the point of global localization (deduced from the DIC strain maps)

(2) The necking strain is lowest for PST, which corresponds to the minimum that is typically found in forming limit diagrams. It may be surprising to see, however, that the BAT necking strain is much larger than that of UAT.

(3) Whereas damage versus strain measurements typically show damage initiation only after a minimum strain threshold, followed by an exponential damage increase [45], here all three load cases show that damage incidents are predominantly initiated at low strain levels, after which the total number of damage incidents saturates. This initial damage burst is particularly evident for BAT.

(4) It is remarkable that the BAT damage evolution trend of $D_{\mathrm{MFI}}$ and $D_{\mathrm{MC}}$ looks very similar, which is also true for the coarse-grained and high martensite microstructures (shown below in Fig. 9). This suggests that both mechanisms are somehow linked.

Interestingly, the first three observations are in agreement with those of Tasan et.al [46], where the total number of damage incidents was measured (only) at the point of necking and failure, for the commercial (parent) DP600 microstructure with the same chemical composition (note that no comparison with observation 4 could be made).

In order to understand these observations, a thorough experimental and numerical analysis, discussed below, was initiated, which led to the following hypothesis on a chain of events that links $D_{\mathrm{MC}}$ to $D_{\mathrm{MFI}}$ :

(a) Plastic straining in F: upon deformation, due to the lower yield strength of ferrite compared to martensite, the ferrite matrix quickly strains plastically.

(b) Fracture of $M$ : especially under biaxial loading, a large hydrostatic stress develops, even at early stage of deformation, causing the smallest or weakest cross section of the typically irregularly shaped martensite islands (or thin martensite bridges) to fracture.

(c) Extreme local straining in $F$ and $D_{M F T}$ : when a martensite island fractures, the surrounding ferrite must carry the released load. This results in extreme local plastic straining, stopped only by the increase in flow stress due to strain hardening. This extreme local straining in ferrite may trigger microdamage, i.e., $D_{\mathrm{MFI}}$ damage.

(d) Diffuse straining in $F$ : a larger area around the damage site needs to increase in strain to accommodate the extreme local strains and to carry the increase in stress due to $D_{\mathrm{MFI}}$.

One can easily see that this hypothesis, in which $D_{\mathrm{MFI}}$ is caused by $D_{\mathrm{MC}}$, can explain the peculiar similarity in BAT trend for $D_{\mathrm{MFI}}$ and $D_{\mathrm{MC}}$ (observation 4). It may also explain why most damage incidents initiate at low strain (observation 3), while at the same time the built up of stress in $M$ explains the relatively high yield strength of DP steels. Moreover, the critical role of hydrostatic stress can explain why $D_{\mathrm{MC}}$ primarily occurs at BAT [ $D_{\mathrm{MC}}$ is negligible for UAT (Fig. 5a) and small for PST (Fig. 5b)]. Furthermore, the coupling of $D_{\mathrm{MFI}}$ to $D_{\mathrm{MC}}$ can explain that 
$D_{\mathrm{MFI}}$ also increases from UAT to PST to BAT (observation 1). Lastly, the diffuse straining in combination with strain hardening may prevent the formation of percolation paths, and thus delaying global localization; such a necking retardation mechanism may explain the large necking strain at BAT (observation 2). Nevertheless, to test the validity of this $D_{\mathrm{MC}}-D_{\mathrm{MFI}}$ hypothesis, additional numerical and experimental studies were conducted, which are presented next.

\section{Microstructural simulations}

First, numerical simulations of the (measured) fine-grained microstructure loaded at UAT, PST, and BAT to $5 \%$ strain are investigated. To this end, Fig. 6 shows the hydrostatic stress and plastic strain fields. Note that the deviatoric stress (or von Mises stress) and volumetric strain are not shown as they scale with the plastic strain and hydrostatic stress, respectively, in the isotropic elasto-plastic model used ("Methodology" section). Also no damage mechanisms were included in these simulations, as they would require the measurement of constitutive laws for damage initiation and growth; the fundamental challenges in obtaining such laws have been described in detail in [31]. Since these simulations do not include damage-induced strain relaxation and stress redistributions, care should be taken when comparing to experimental results.
Nevertheless, the simulations do provide qualitative insight in the differences in stress and strain state for the different strain paths.

Figure $6 \mathrm{a}-\mathrm{c}$ shows that the equivalent plastic strain is higher in the ferrite matrix than the martensite islands and shows strain bands between 45 and $60^{\circ}$ to the main loading direction, in agreement with [30]. Regarding the plastic strain magnitude and distribution in the ferrite, it is observed that, from BAT to PST to UAT, the strain localizes increasingly into peaks. Based on this trend, a decrease in $D_{M F I}$ from UAT to BAT would be expected; however, the opposite is observed in Fig. 5, which indicates that another mechanism for damage in ferrite becomes active at PST and especially BAT.

The plastic straining releases the deviatoric stress in the ferrite matrix and, through stress redistribution (bounded by stress equilibrium at the phase boundaries), also the hydrostatic stress. This is seen in Fig. 6d-f, which shows that the hydrostatic stress is (much) higher in the martensite islands. Naturally, the hydrostatic stress increases with the change of loading from UAT to PST to BAT. This increase in hydrostatic stress explains the observed increase in fracture of martensite (i.e., $D_{\mathrm{MC}}$ ) from UAT to PST to BAT (Fig. 5).

The simulations thus support the first two steps of the $D_{\mathrm{MC}}-D_{\mathrm{MFI}}$ hypothesis; however, because of the absence of damage mechanisms, the last two steps (regarding the coupling between $D_{\mathrm{MC}}$ and $D_{\mathrm{MFI}}$ ) cannot be investigated.
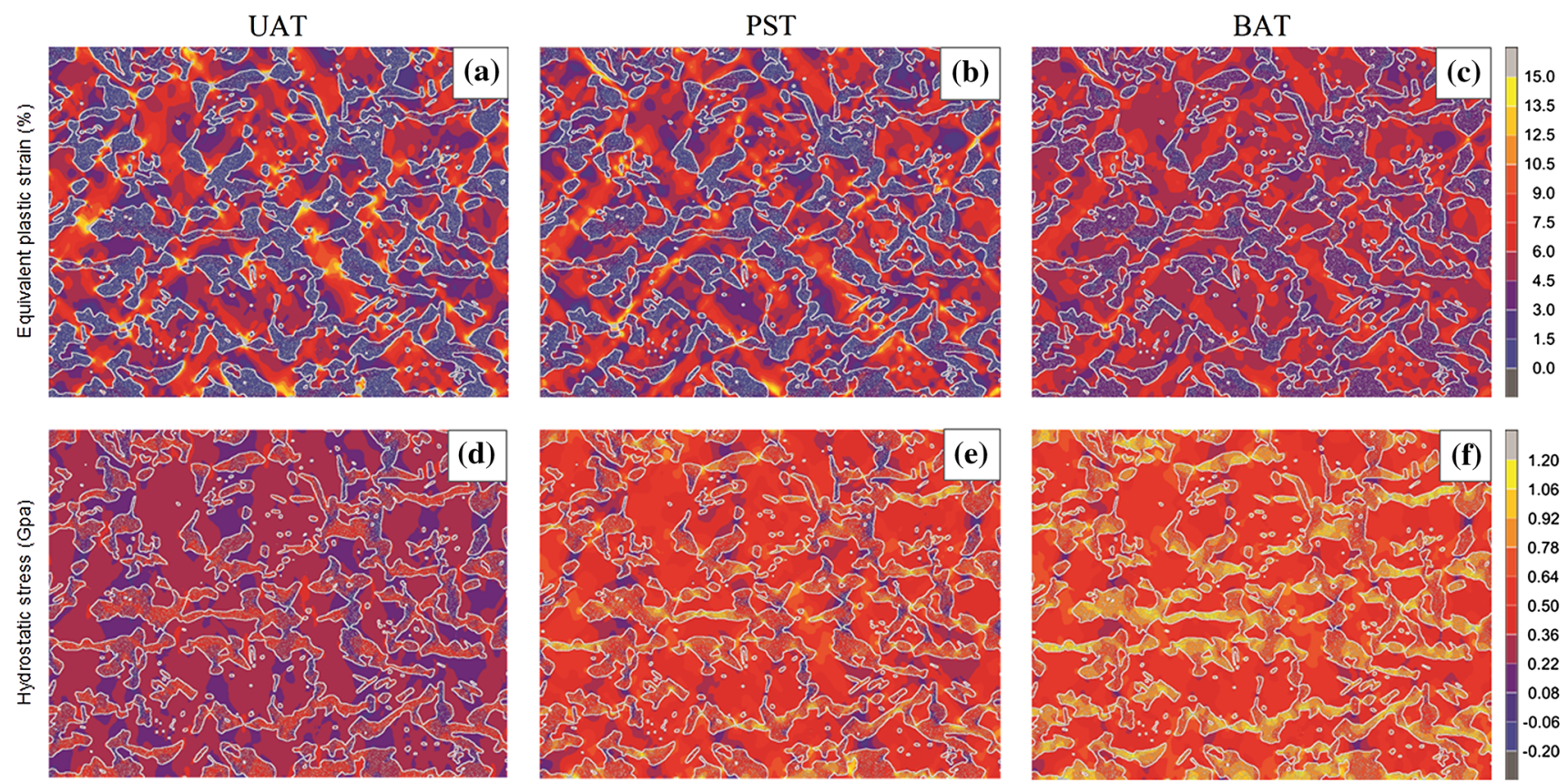

Fig. 6 FEM simulation results for the fine microstructure $\left(\mu_{\mathrm{FG}}\right)$, deformed to a global von Mises equivalent strain of $5 \%$, for UAT, PST, and BAT. a-c The local equivalent plastic strain (in \%). d-f The hydrostatic stress (in GPa). A white line demarks the martensite- ferrite phase boundaries and a fine white speckled pattern was added on the martensite phase to make it distinguishable from the ferrite phase. A map of the martensite-ferrite microstructural distribution is shown in Fig. 1a 
Hence, two additional experiments were performed to examine the connection between $D_{\mathrm{MC}}$ and $D_{\mathrm{MFI}}$.

\section{In-situ SEM study}

In the first additional experiment to study the evolution of individual damage incidents during the deformation, biaxial tension tests up to failure were performed in situ under SEM (SE-mode) observation using home-built miniaturized Marciniak setup, shown in Fig. 2a. The measured large-area $\left(300 \times 300 \mu^{2}\right)$ in-situ SEM movies were analyzed in detail with respect to martensite cracking incidents and further deformation around these $D_{\mathrm{MC}}$ sites. First of all, it was found that the areal density of $D_{\mathrm{MC}}$ incidents at the surface was significantly lower than in the bulk, which is attributed to the lower hydrostatic stress at the surface. Still, many $D_{\mathrm{MC}}$ incidents could be observed under biaxial loading, of which seven examples are given in Fig. 7. It was found that most $D_{\mathrm{MC}}$ incidents occurred in the smallest cross section of the irregularly shaped martensite islands, i.e., the thin martensite bridges. Moreover, it was observed that almost all $D_{\mathrm{MC}}$ incidents initiated at the early stages of deformation, see Fig. 7b, and that $D_{\mathrm{MC}}$ incidents were typically accompanied by one or more location of extreme plasticity in the surrounding ferrite, see Fig. 7c. This would be counted as $D_{\text {MFI }}$ damage in the damage quantification methodology, giving direct evidence for the hypothesis that $D_{\mathrm{MC}}$ triggers $D_{\mathrm{MFI}}$. Finally, it should be noted that around most $D_{\mathrm{MC}}-D_{\mathrm{MFI}}$ locations the localized extreme plastic straining spreads out into the neighboring ferrite grains resulting in diffuse deformation zones that can cover the complete ferrite grain, see Fig. 7d, thus supporting the necking retardation mechanism of the hypothesis. This mechanism of ferrite damage (i.e., highly localized ferrite deformation) activating diffuse deformation zones in the adjacent ferrite grains was also observed in situ in the microstructural martensite bands observed in commercial DP600 sheet [30]. Combining Figs. 5 and 7, it can be concluded that the early-initiated martensite cracking incidents are well enough dispersed to postpone the formation of percolation paths, which explains the late global localization.

\section{$3 D$ depth profiling}

In the second additional experiment to investigate whether the coupling between $D_{\mathrm{MC}}$ and $D_{\mathrm{MFI}}$ damage initiation is also present in the specimen interior, high-resolution $3 \mathrm{D}$ depth profiling is performed on the cross section of a $16 \%$ biaxially strained fine-grained specimen. To this end, a series of flat profiles are made approximately $300 \mathrm{~nm}$ apart. Note that the high requirements on surface roughness rule out the (Nital) surface etching, used before to distinguish between martensite and ferrite phases. Instead, precision polishing is used to reproducibly remove a $\sim 300 \mathrm{~nm}$ surface layer, while SEM imaging in backscatter electron (BSE) imaging mode is used to identify the martensite and ferrite phases by the difference in channeling contrast (note that martensite shows much finer spatial variations in channeling contrast due to its much finer substructure compared to that of the relatively coarse ferrite sub-grains). This identification procedure was verified in detail using electron backscatter diffraction analysis (not shown). Note also that, due to the channeling contrast, $D_{\mathrm{MC}}$ and especially $D_{\mathrm{MFI}}$ damage locations appear differently.

Three typical examples of the detailed 3D shape of a $D_{\mathrm{MC}}$ damage location are shown in Fig. 8. A number of observations could be made from these and other depth profiles measured in the specimen interior.

(1) As expected, the 3D shape of the martensite islands is irregular and the fracture occurs always at the smallest cross section, or at least a small cross section. In other words, the microstructural configuration within the martensite islands seems to be play a secondary role, in agreement with [47].

(2) The $D_{\mathrm{MC}}$ locations are typically surrounded on one or both sites by a $D_{\mathrm{MFI}}$ location, see, e.g., micrographs $\mathbf{b}$ and $\mathbf{i}$ in Fig. 8. This is a strong indication that martensite cracking triggers martensite-ferrite interface damage, because the force previously carried by the martensite island must be fully transferred to the neighboring ferrite matrix after the martensite cracking. Notice also that $D_{\mathrm{MC}}$-to$D_{\mathrm{MFI}}$ mechanism is activated already at the relatively low small strain of $16 \%$, in agreement with Fig. 7c. (3) The fact that the $D_{\mathrm{MFI}}$ location has opened up and has therefore become visible for micrographic observation in the SEM-BSE images also means that the surrounding ferrite must have strained heavily to accommodate the martensite crack opening displacement, which is typically in the order of hundreds of nanometers.

In addition, all recorded high-resolution SEM-BSE images (with a total area of $38200 \mu \mathrm{m}^{2}$ ) were processed with the above-mentioned damage quantification methodology, i.e., similar to Fig. 5. A total of 202 damage incidents were automatically found by the software and identified as $D_{\mathrm{MC}}, D_{\mathrm{MFI}}, D_{\mathrm{FGB}}, D_{\mathrm{FGI}}$, or $D_{\mathrm{INC}}$. Again $D_{\mathrm{MFI}}$ and $D_{\mathrm{MC}}$ damage dominated showing a mutual ratio of $\sim 1.7$ in good agreement with the ratio found in Fig. $5 \mathrm{c}$ at $16 \%$ strain, especially when considering the differences in image contrast mode used. Detailed investigation of the 3D connections revealed that the 202 damage counts in these stacked images could be traced back to 81 3D damage zones and approximately half of the $D_{\mathrm{MFI}}$ incidents 
Fig. 7 Seven examples of insitu SEM observation (at the specimen surface) of the finegrained microstructure (a), which exhibits damage evolution under biaxial loading initiated by martensite cracking (solid circles in images (b)) at the early stages of deformation, followed by extreme localized plasticity in the surrounding ferrite (arrows in images (c)), followed by large deformation zones (dashed ellipses in images (d)). All images are sized $10 \times 10 \mu \mathrm{m}^{2}$
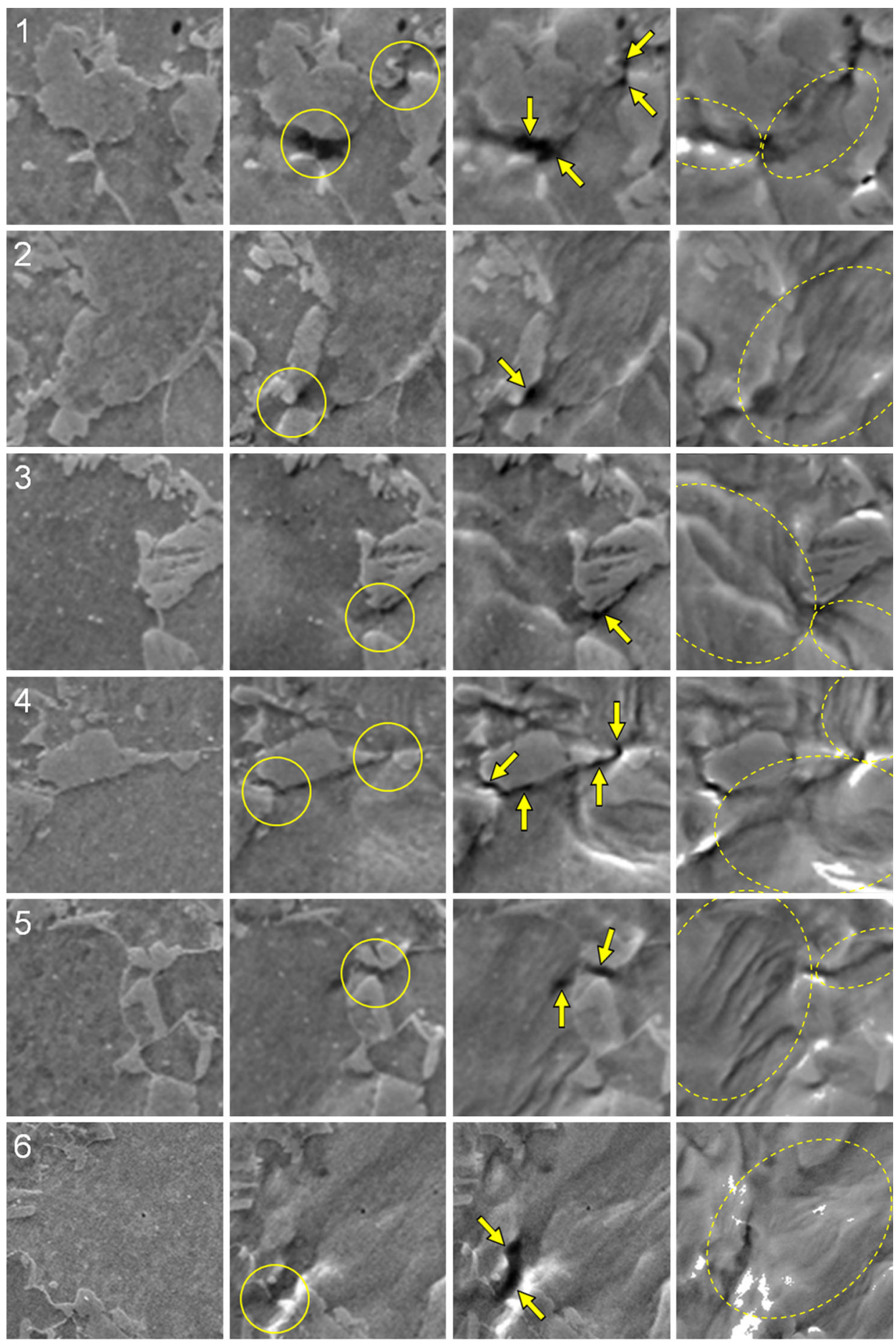

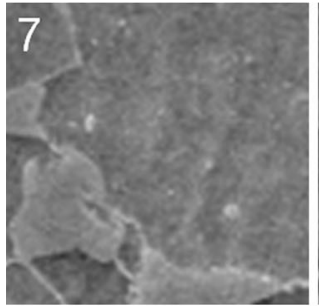

(a) before BAT test

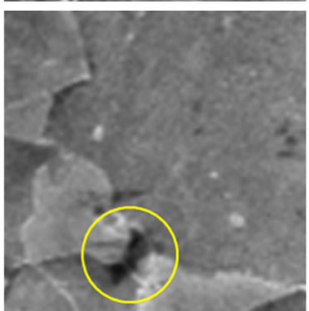

(b) $\boldsymbol{\varepsilon}_{\text {Mises }}=4.0 \%$

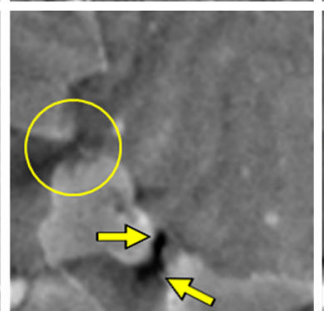

(c) $\boldsymbol{\varepsilon}_{\text {Mises }}=11.9 \%$

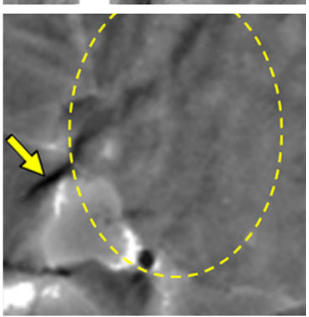

(d) $\boldsymbol{\varepsilon}_{\text {Mises }}=29.5 \%$ 
Fig. 8 High-resolution 3D profiles of typical damage incidents in the specimen interior in BAT-strained $\left(\varepsilon_{\text {Mises }}=16 \%\right)$ fine-grained $\left(\mu_{\mathrm{FG}}\right)$ microstructure, consistently showing a martensite crack at its center (e.g., image $f$ of damage incident $(i)$ ) surrounded by severe plastic straining location (e.g., image $b$ 'above' and image $i$ 'below'). The depth profile layers are separated $\sim 300 \mathrm{~nm}$ (along one of the two loading directions, LD) and the SEM channeling contrast images were taken halfway through the sheet thickness direction (TD)

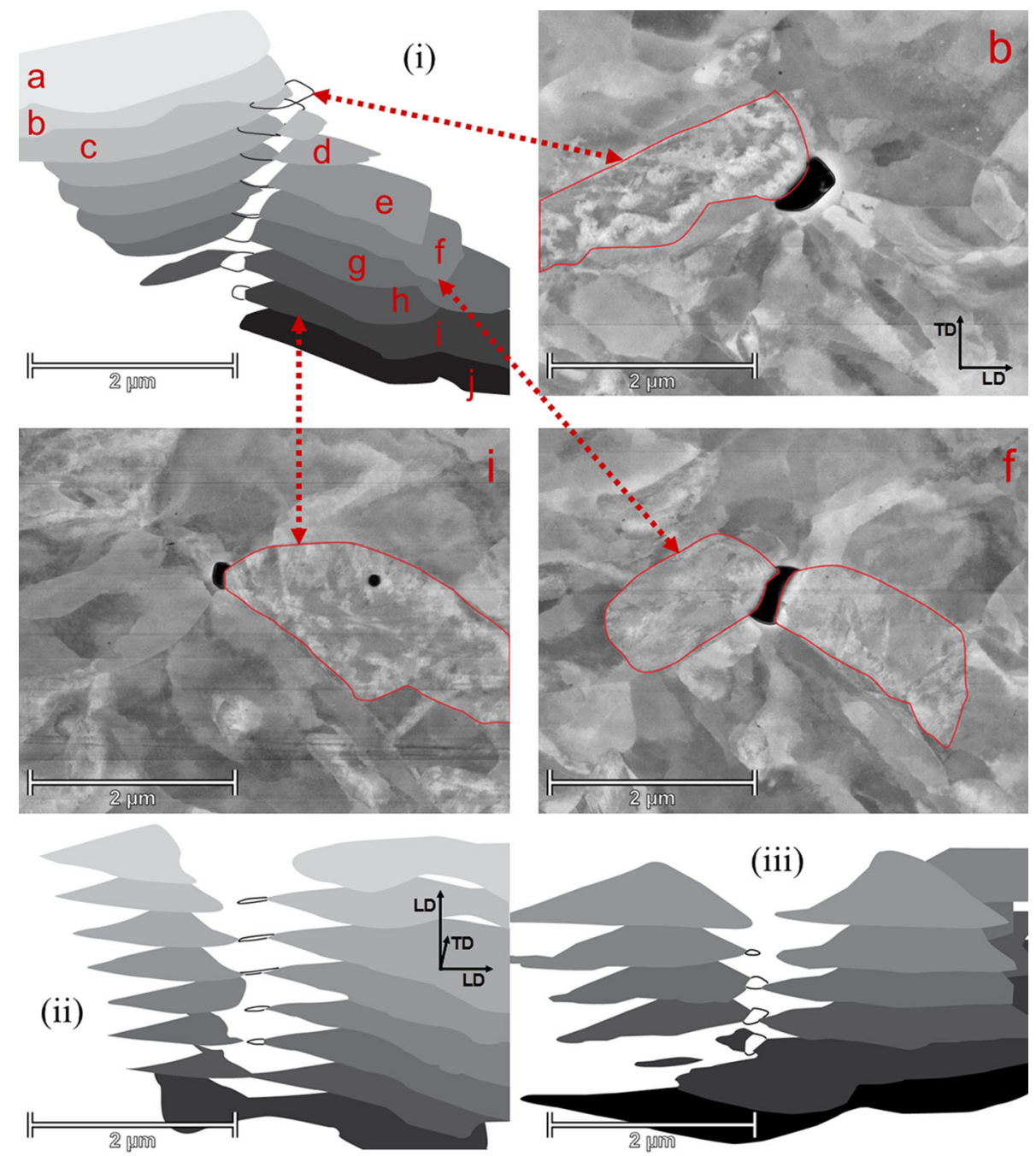

originate from a martensite cracking event $\left(D_{\mathrm{MC}}\right)$, which may explain the increase in $D_{\mathrm{MFI}}$ from PST to BAT loading, observed in Fig. 5.

Finally, it is noted that, with this insight in the 3D character of coupled $D_{\mathrm{MC}}-D_{\mathrm{MFI}}$ damage incidents, it cannot be excluded that the damage incidents at a ferrite grain boundary or inside the grain interior $\left(D_{\mathrm{FGB}}\right.$ and $\left.D_{\mathrm{FGI}}\right)$ are in fact caused by a martensite island above or below the surface of observation, and thus should have been counted as $D_{\mathrm{MFI}}$. However, due to the relative unimportance of $D_{\text {FGB }}$ compared to $D_{\text {FGI }}$, this would not alter the conclusions.

\section{Conclusions part $A$}

In all, it can be concluded that the $D_{\mathrm{MFI}}-D_{\mathrm{MC}}$ hypothesis is supported by many different forms of experimental and numerical evidence. Especially, the mechanism that spreads out the deformation over a larger ferrite area (the diffuse deformation zones) is interesting, as it seems to be the cause for the delay of global localization. For this necking retardation mechanism to be effective, however, the damage incidents need to be well enough dispersed, such that the early burst of $D_{\mathrm{MC}}$ damage in BAT does not result in global localization by connection of $D_{\mathrm{MC}}$ damage localizations. Therefore, next, the influence of microstructure features (grain size and martensite volume percentage) is investigated.

\section{Variation of microstructure}

Figure 9 compares the BAT deformation of the finegrained $\left(\mu_{\mathrm{FG}}\right)$, coarse-grained $\left(\mu_{\mathrm{CG}}\right)$, and high martensite $\left(\mu_{\mathrm{HM}}\right)$ microstructures, with respect to the damage incident densities obtained with the damage quantification methodology (Fig. 9a-c), the simulated hydrostatic stress fields (Fig. 9d-f), and simulated plastic strain fields (Fig. 9g-i). All three microstructures show very similar damage density evolutions, with $D_{\mathrm{MFI}}$ being approximately twice as much as $D_{\mathrm{MC}}$ and more than four times larger than the three other mechanisms $\left(D_{\mathrm{FGB}}, D_{\mathrm{FGI}}\right.$, and $\left.D_{\mathrm{INC}}\right)$, and $D_{\mathrm{MFI}}$ and $D_{\mathrm{MC}}$ showing roughly the same trend with a steep 

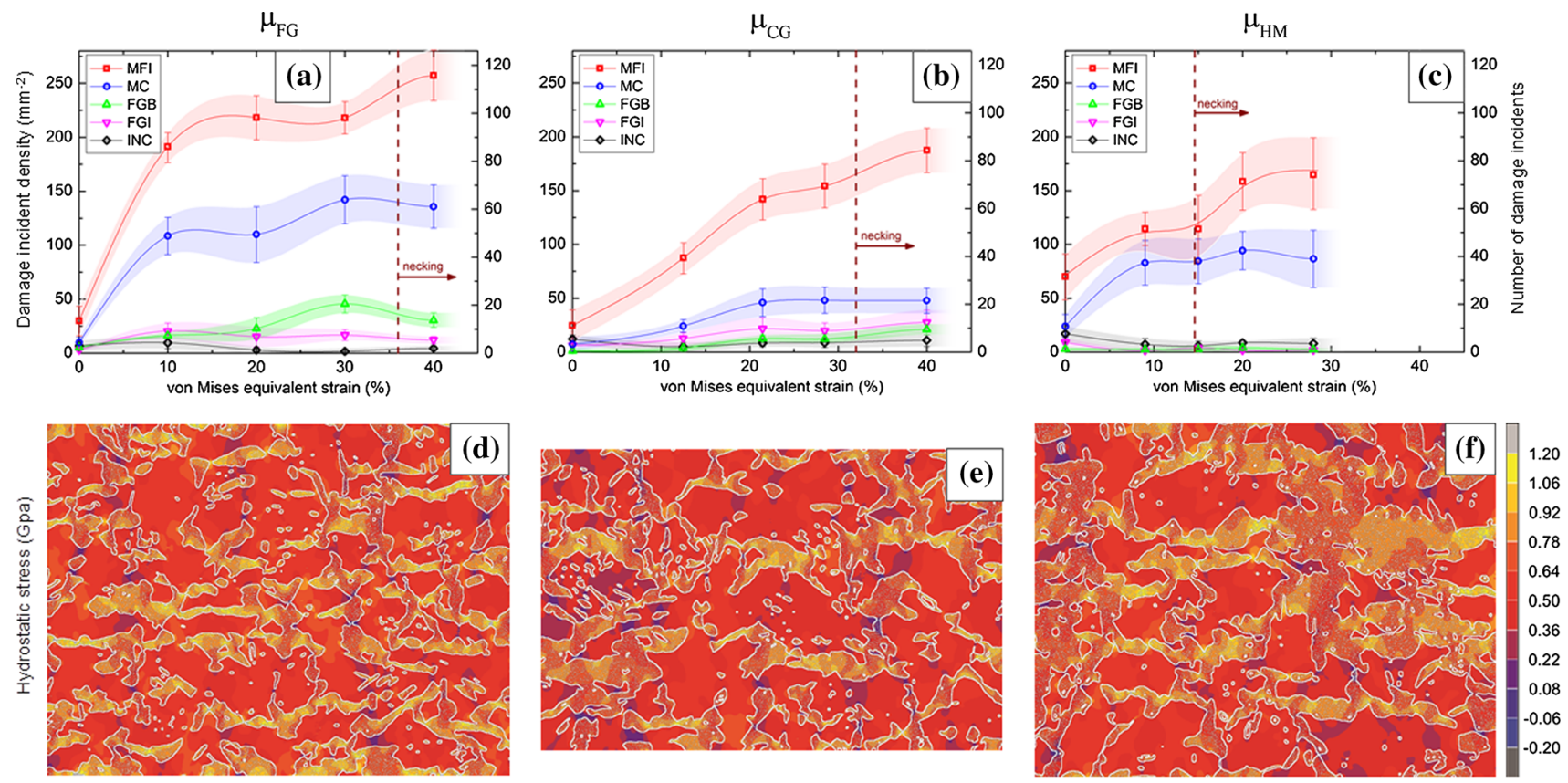
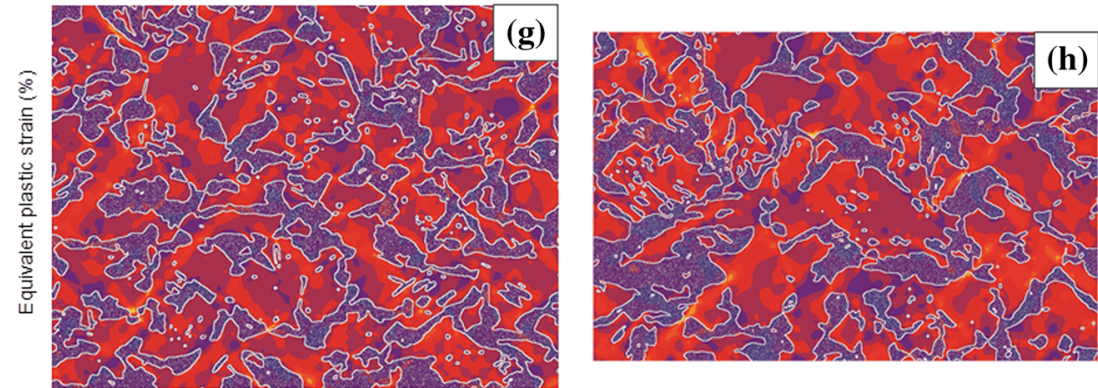

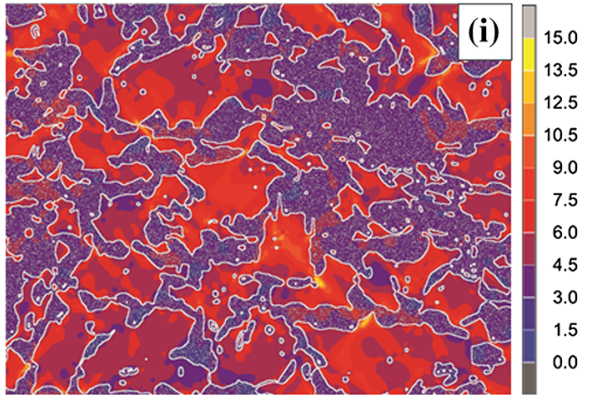

Fig. 9 Experimental and numerical results for BAT, comparing finegrained $\left(\mu_{\mathrm{FG}}\right)$, coarse-grained $\left(\mu_{\mathrm{CG}}\right)$, and high martensite $\left(\mu_{\mathrm{HM}}\right)$ microstructures. a-c Damage incident density versus equivalent strain, quantified from five $300 \times 300 \mu \mathrm{m}^{2}$ SEM scans for each data point (error bars represent standard deviation; dashed vertical lines show point of global localization). FEM simulations at a global von Mises equivalent strain of $5 \%$ of $\mathbf{d}-\mathbf{f}$ the local equivalent plastic

initial increase that reduces toward higher strains already before the point of necking. This suggests that the abovementioned causal connection between $D_{\mathrm{MFI}}$ and $D_{\mathrm{MC}}$ is also active at larger grain size and higher martensite content. On a more subtle note, for $\mu_{\mathrm{CG}}$, the ratio of $\mathrm{D}_{\mathrm{MFI}}$ to $\mathrm{D}_{\mathrm{MC}}$ is slightly larger than those for the two other microstructures and the initial increase of $\mathrm{D}_{\mathrm{MC}}$ is slightly less steeper. Perhaps, the number of "thin martensite bridges" is lower for the $\mu_{\mathrm{CG}}$ microstructure which leads to fewer MC incidents.

\section{Influence of grain size}

The isolated influence of grain size is investigated by comparing the $\mu_{\mathrm{FG}}$ and $\mu_{\mathrm{CG}}$ microstructures: a reduction in grain size corresponds to an increase in $D_{\mathrm{MFI}}$ and $D_{\mathrm{MC}}$ strain and $\mathbf{g}-\mathbf{i}$ the hydrostatic stress. Same color scale bars as in Fig. 6 are used for easy comparison. A white line demarks the martensiteferrite phase boundaries in $(\mathbf{d}-\mathbf{i})$ and a fine white speckled pattern was added on the martensite phase to make it distinguishable from the ferrite phase. A map of the martensite-ferrite microstructural distribution is shown in, respectively, Fig. 1a-c

densities and, especially, earlier damage initiation at low strains (Fig. 9a, b). These effects could be caused by the same grain size effect underlying the well-known HallPetch relation between the yield (and flow) strength and the grain size, which is explained by the obstruction of plastic slip at the grain and/or phase boundaries causing dislocation pile-up, thereby locally increasing the stress level at the boundaries. Indeed, the experimental global stressstrain curves in Fig. 1d show this increase in yield and flow strength. The $D_{\mathrm{MFI}}-D_{\mathrm{MC}}$ hypothesis would predict that a faster rise of the stress level at the martensite-ferrite boundaries (due to a reduction in ferrite grain size) results in more and earlier $D_{\mathrm{MC}}$ damage and, due to the $D_{\mathrm{MC}}-D_{\mathrm{MFI}}$ causality, in more $D_{\mathrm{MFI}}$ damage, thus explaining the observed differences between Fig. 9a, b. The evolutions of the simulated hydrostatic stress also show significantly 
higher stress concentrations in the martensite islands of the $\mu_{\mathrm{FG}}$ microstructure, but this is a direct result of the higher ferrite yield strength used, see Table 1, which indirectly takes into account the Hall-Petch effect.

\section{Influence of martensite volume fraction}

To investigate the isolated influence of martensite volume fraction, next, the $\mu_{\mathrm{CG}}$ and $\mu_{\mathrm{HM}}$ microstructures are compared: an increase in martensite volume fraction results in an increase in $D_{\mathrm{MC}}$ damage, whereas it does not seem to significantly impact $D_{\mathrm{MFI}}\left(\right.$ Fig. 9b, c). The increase in $D_{\mathrm{MC}}$ is attributed to the stress increase due to the reduction of plastically deforming ferrite phase resulting in a compact network of the harder martensite phase. Indeed, a pronounced increase in stress level (at equal global strain) is seen in the simulated hydrostatic stress fields (Fig. 9e versus 9f). Interestingly, the increase in $D_{\mathrm{MC}}$ with increasing martensite volume fraction is not followed by an increase of $D_{\text {MFI. }}$. This may be the result of the lower probability that a $D_{\mathrm{MC}}$ location is adjacent to an open ferrite area that is large enough (and thus the constraint by the surrounding martensite network low enough) to develop extreme localized plasticity, identified as $D_{\mathrm{MFI}}$. As a direct consequence, the areal density of diffuse deformation zones, which are initiated from a $D_{\text {MFI }}$ sites as shown in Fig. 7d, will also be lower. This is precisely what is also seen in the simulated fields of the plastic strain, which for higher martensite volume fraction shows large regions with low ferrite strain, see, e.g., the lower left corner of Fig. 9i. In other words, the compact martensite network in the $\mu_{\mathrm{HM}}$ microstructure prevents the plastic straining around a $D_{\mathrm{MC}}$ location from spreading out to surrounding ferrite grains. Indeed, as a consequence of the fact that this spreading of plastic straining is hampered, Fig. 9i also reveals a number of local spots where the plastic strain peaks to a level far above the maximum strain found in Fig. 9g, h.

\section{Retardation of plastic instability}

Let us next focus on the global localization behavior of these three microstructures. Comparing the necking behavior of $\mu_{\mathrm{CG}}$ with $\mu_{\mathrm{HM}}$, a large reduction in global localization strain is observed, which can be related to the increase in martensite volume fraction. Global localization involves connection of the above-mentioned diffuse deformation zones into a global strain percolation path, which, for DP steel, will obviously run through the available ferrite grains. For $\mu_{\mathrm{HM}}$, less strain percolation paths form, and hence each percolation path must strain more to accommodate the same applied global strain, therefore earlier reaching the point of global localization. This reduction of the number of percolation paths is clearly seen in Fig. 9i, which only shows one pronounced percolation path (running from upper left to lower right corner).

Figure 9 also shows that necking takes place at higher equivalent strain for $\mu_{\mathrm{FG}}$ compared to $\mu_{\mathrm{CG}}$. Because the martensite volume fraction is the same for $\mu_{\mathrm{FG}}$ and $\mu_{\mathrm{CG}}$, another mechanism must be at play, which may be explained as follows. Global localization is controlled by the weakest percolation path and, for $\mu_{\mathrm{CG}}$ compared to $\mu_{\mathrm{FG}}$, less diffuse deformation zones need to be connected to complete a percolation path over the full sample thickness or width. Therefore, taking into account the large spread of grain properties and geometries, the percolation paths in $\mu_{\mathrm{CG}}$ will exhibit a larger variability. As a result, the strength of the critical (weakest) percolation path will be smaller in $\mu_{\mathrm{CG}}$, which explains its lower global localization strain. The same mechanism was found to control the necking behavior observed in tensile tests of aluminum strips with very few grains over the specimen width [48], for which in-situ DIC strain maps showed direct evidence that weaker localized percolation paths develop when the grain size is increased, triggering earlier global localization. For our case, this possible explanation would indeed be supported by the strain fields in Fig. 9g, h, which shows that the number of percolation paths is higher in the $\mu_{\mathrm{FG}}$ microstructure.

Finally, when the case of $\mu_{\mathrm{FG}}$ is directly compared to that of $\mu_{\mathrm{HM}}$, it is interesting to note that the damage evolution at small strains looks quite similar, see Fig. 9a, c. However, there is a major difference, which exhibits itself in the observation of a higher flow stress as well as a higher fracture strain, see Fig. 1d. Of course, the above-mentioned Hall-Petch effect could explain the increase in flow stress; however, there exists a well-known competition between high strength versus high elongation. Therefore, to explain the observed increase in fracture strain for $\mu_{\mathrm{FG}}$ compared to $\mu_{\mathrm{HM}}$ another mechanism is required. As was seen above, for $\mu_{\mathrm{HM}}$, the high hydrostatic stresses are a direct result from the limitation in the number of strain percolation paths, which also localizes the damage evolution causing earlier global localization and final fracture (Fig. 9c). For $\mu_{\mathrm{FG}}$, on the other hand, the damage is more dispersed due to its finer microstructure and more ferrite grains, which activates the necking retardation mechanism in which damage initiation triggers (many) diffuse deformations zones, as was seen in Fig. 7, thereby spreading out plastic straining and thus postponing global localization. Hence, for $\mu_{\mathrm{FG}}$, the high hydrostatic stress does not seem to be detrimental, but actually beneficial as it increases the global flow strength compared to $\mu_{\mathrm{HM}}$ (shown in Fig. 1d for the global stress-strain curves under uniaxial tension). This would mean that the well-known competition between high strength versus high elongation can be overcome by 
inserting many barriers in the microstructure that increase the hydrostatic stresses. It is crucial, however, that these barriers break open easily enough (as is the case in $\mu_{\mathrm{FG}}$ and not in $\mu_{\mathrm{HM}}$ ) such that plasticity spreads out subsequently to the surrounding matrix in order to prevent early necking.

\section{Microstructure design}

The role of the damage mechanisms in the localization and fracture behavior is critical. Without damage mechanisms, there is no stress release by diverging localized plasticity to non-local (diffuse) plasticity, thus the stress keeps on building up, leading to early necking. Of course, stress release can only activate a necking retardation mechanism when damage sets in before strain percolation paths have formed. In turn, early damage formation requires high hydrostatic stress built up at early stages of deformation, which can be achieved by microstructural refinement due to the grain size effect, while it also strongly depends on the loading conditions. For instance, for BAT, much higher hydrostatic stresses build up compared to UAT and PST, see Fig. 6, which may explain the unusually high BAT necking strain (Fig. 5) compared to typical forming limit diagrams which show the highest necking strain for UAT.

Based on these insights, it is anticipated that the ideal microstructure combining high strength with high ductility can be achieved through microstructural refinement, e.g., by careful design of a nano-grained DP. The hard phase (e.g., martensite) should be tailored to surround the softer grains with an approximately uniform layer that is strong enough to drive up the stress, but with enough weak spots that can lead to damage relatively easily, resulting in a high dispersion of damage locations, each activating a diffuse deformation zone, and thereby effectively retarding global localization. This mechanism may be the underlying reason for the recent success of nano-grain dual-phase steels [9]. The diffuse deformation and resulting strain hardening in the ferrite grains adjacent to the voids may also explain earlier observations that for DP steels the classical mechanism of ductile failure through void initiation, growth, and coalescence only becomes relevant close to the moment of final failure, i.e., after global localization has set in [46].

\section{General conclusions}

An extensive experimental-numerical campaign was set up to characterize, in a statistically relevant manner, the evolution of the key ductile damage mechanisms up to failure, for three strain paths and three well-controlled dual-phase microstructures. From the in-depth analysis, the following main conclusions can be drawn:
- A chain of damage events was hypothesized, in which plastic straining in ferrite grains triggers fracture of martensite islands and subsequently damage in neighboring ferrite, causing diffuse straining in a larger ferrite area. This hypothesis is supported by various direct and indirect evidence.

- An interesting necking retardation mechanism was elucidated, in which the diffuse straining in combination with strain hardening may postpone the formation of a global strain percolation path. This mechanism is enhanced for finer microstructures, in which the damage initiation sites as well as the resulting diffuse deformations zones are more dispersed.

Based on these new insights, a route to circumvent the well-known competition between high strength versus high elongation was proposed by exploiting the concept of microstructural refinement to greater depths.

Acknowledgements The authors gratefully acknowledge the contributions of Marc van Maris, Patrick Schoenmakers, Chaowei Du, Dingshun Yan, Carel ten Horn, and Henk Vegter.

Open Access This article is distributed under the terms of the Creative Commons Attribution 4.0 International License (http://creativecommons.org/licenses/by/4.0/), which permits unrestricted use, distribution, and reproduction in any medium, provided you give appropriate credit to the original author(s) and the source, provide a link to the Creative Commons license, and indicate if changes were made.

\section{References}

1. Grässel O, Kruger L, Frommeyer G, Meyer LW (2000) High strength Fe-Mn-(Al, Si) TRIP/TWIP steels development-properties-application. Int J Plast 16:1391-1409. doi:10.1016/ S0749-6419(00)00015-2

2. Barbier D, Gey N, Allain S, Bozzolo N, Humbert M (2009) Analysis of the tensile behavior of a TRIP steel based on the texture and microstructure evolutions. Mat Sci Eng A 500:196-206. doi:10.1016/j.msea.2008.09.031

3. Speer JG, Assuncao FCR, Matlock DK, Edmonds DV (2005) The "quenching and partitioning" process: background and recent progress. Mater Res 8:417-423. doi:10.1590/S151614392005000400010

4. Edmonds DV, He K, Rizzo FC, De Cooman BC, Matlock DK, Speer JG (2006) Quenching and partitioning martensite-a novel steel heat treatment. Mat Sci Eng A 440:25-34. doi:10.1016/j. msea.2006.02.133

5. Caballero FG, Bhadeshia HKDH (2004) Very strong bainite. Curr Opin Solid State Mater 8:251-257. doi:10.1016/j.cossms.2004. 09.005

6. Bhadeshia HKDH (2010) Nanostructured bainite. Proc R Soc A 466:3-18. doi:10.1098/rspa.2009.0407

7. Rashid MS (1981) Dual phase steels. Ann Rev Mater Sci 11:245-266. doi:10.1146/annurev.ms.11.080181.001333

8. Llewellyn DT, Hillis DJ (1996) Dual phase steels. IronmakSteelmak 23:278-471

9. Calcagnotto M, Ponge D, Raabe D (2010) Effect of grain refinement to $1 \mu \mathrm{m}$ on strength and toughness of dual-phase 
steels. Mat Sci Eng A 527:7832-7840. doi:10.1016/j.msea.2010. 08.062

10. Calcagnotto M, Ponge D, Demir E, Raabe D (2010) Orientation gradients and geometrically necessary dislocations in ultrafine grained dual-phase steels studied by $2 \mathrm{D}$ and 3D EBSD. Mater Sci Eng A 527:2738-2746. doi:10.1016/j.msea.2010.01.004

11. Asadi M, De Cooman BC, Palkowski H (2012) Influence of martensite volume fraction and cooling rate on the properties of thermomechanically processed dual phase steel. Mater Sci Eng A 538:42-52. doi:10.1016/j.msea.2012.01.010

12. Son YI, Lee YK, Park K-T, Lee CS, Shin DH (2005) Ultrafine grained ferrite-martensite dual phase steels fabricated via equal channel angular pressing: microstructure and tensile properties. Acta Mater 53:3125-3134. doi:10.1016/j.actamat.2005.02.015

13. Delincé M, Jacques PJ, Pardoen T (2006) Separation of sizedependent strengthening contributions in fine-grained dual phase steels by nanoindentation. Acta Mater 54:339503404. doi:10. 1016/j.actamat.2006.03.031

14. Ahmad E, Manzoor T, Ali KL, Akhter JI (2000) Effect of microvoid formation on the tensile properties of dual-phase steel. J Mater Eng Perform 9:306-310. doi:10.1361/105994900770345962

15. Bouaziz O, Iung T, Kandel M, Lecomte C (2001) Physical modelling of microstructure and mechanical properties of dualphase steel. J Phys IV France 11:223-231. doi:10.1051/jp4: 2001428

16. Rodriguez R-M, Gutiérrez I (2003) Unified formulation to predict the tensile curves of steels with different microstructures. Mater Sci Forum 2003:426-432

17. Ramazani A, Mukherjee K, Schwedt A, Goravanchi P, Prahl U, Bleck W (2013) Quantification of the effect of transformationinduced geometrically necessary dislocations on the flow-curve modeling of dual-phase steels. Int J Plast 43:128-152. doi:10. 1016/j.ijplas.2012.11.003

18. Das D, Chattopadhyay PP (2009) Influence of martensite morphology on the work-hardening behavior of high strength ferritemartensite dual-phase steel. J Mater Sci 44:2957-2965. doi:10. 1007/s10853-009-3392-0

19. Avramovic-Cingara G, Ososkov Y, Jain MK, Wilkinson DS (2009) Effect of martensite distribution on damage behaviour in DP600 dual phase steels. Mater Sci Eng A 516:7-16. doi:10. 1016/j.msea.2009.03.055

20. Sun X, Choi KS, Liu WN, Khaleel MA (2009) Predicting failure modes and ductility of dual phase steels using plastic strain localization. Int J Plast 25:1888-1909. doi:10.1016/j.ijplas.2008. 12.012

21. Davies RG (1978) Influence of martensite composition and content on the properties of dual phase steels. Metall Trans A 9:671-679. doi:10.1007/BF02659924

22. Marder AR (1982) Deformation characteristics of dual-phase steels. Metall Trans A 13:85-92. doi:10.1007/BF02642418

23. He XJ, Terao N, Berghezan A (1984) Influence of martensite morphology and its dispersion on mechanical properties and fracture mechanisms of Fe-Mn-C dual phase steels. Met Sci 18:367-373. doi:10.1179/030634584790419953

24. Ray RK (1984) Tensile fracture of a dual-phase steel. Scr Metall Mater 18:1205-1209. doi:10.1016/0036-9748(84)90106-6

25. Suh D, Kwon D, Lee S, Kim NJ (1997) Orientation dependence of microfracture behavior in a dual-phase high-strength low-alloy steel. Metall Mater Trans A 28:504-509. doi:10.1007/s11661997-0152-0

26. Maire E, Bouaziz O, Di Michiel M, Verdu C (2008) Initiation and growth of damage in a dual-phase steel observed by X-ray microtomography. Acta Mater 56:4954-4964. doi:10.1016/j.acta mat.2008.06.015

27. Avramovic-Cingara G, Saleh C, Jain MK, Wilkinson DS (2009) Void nucleation and growth in dual-phase steel 600 during uniaxial tensile testing. Metall Mater Trans A 40:3117-3127. doi:10.1007/s11661-009-0030-z

28. Sun X, Choi KS, Soulami A, Liu WN, Khaleel MA (2009) On key factors influencing ductile fractures of dual phase (DP) steels. Mater Sci Eng A 526:140-149. doi:10.1016/j.msea.2009.08.010

29. Tasan CC, Hoefnagels JPM, Geers MGD (2009) A critical assessment of indentation-based ductile damage quantification. Acta Mater 57:4957-4966. doi:10.1016/j.actamat.2009.06.057

30. Tasan CC, Hoefnagels JPM, Geers MGD (2010) Microstructural banding effects clarified through micrographic digital image correlation. Scr Mater 62:835-838. doi:10.1016/j.scriptamat. 2010.02.014

31. Tasan CC, Hoefnagels JPM, Geers MGD (2012) Identification of the continuum damage parameter: an experimental challenge in modeling damage evolution. Acta Mater 60:3581-3589. doi:10. 1016/j.actamat.2012.03.017

32. Kadkhodapour J, Butz A, Ziaei-Rad S (2011) Mechanisms of void formation during tensile testing in a commercial, dual-phase steel. Acta Mater 59:2575-2588. doi:10.1016/j.actamat.2010.12. 039

33. Al-Abbasi FM, Nemes JA (2008) Predicting the ductile failure of DP-steels using micromechanical modeling of cells. Int J Damage Mech 17:447-472. doi:10.1177/1056789507077441

34. Uthaisangsuk V, Prahl U, Bleck W (2008) Micromechanical modelling of damage behaviour of multiphase steels. Comput Mater Sci 43:27-35. doi:10.1016/j.commatsci.2007.07.035

35. Marder AR (1981) The effect of heat treatment on the properties and structure of molybdenum and vanadium dual-phase steels. Metall Trans A 12:1569-1579. doi:10.1007/BF02643562

36. Goel NC, Chakravarty JP, Tangri K (1985) The influence of starting microstructure on the retention and mechanical stability of austenite in an intercritically annealed-low alloy dual-phase steel. Metall Trans A 18:5-9. doi:10.1007/BF02646215

37. Huppi GS, Matlock DK, Krauss G (1980) An evaluation of the importance of epitaxial ferrite in dual-phase steel microstructures. Scr Metall Mater 14:1239-1243. doi:10.1016/0036-9748(80) 90264-1

38. Ramos LF, Matlock DK, Krauss G (1979) On the deformation behavior of dual-phase steels. Metall Trans A10:259-261. doi:10. 1007/BF02817636

39. Cai X-L, Feng J, Owen WS (1984) The dependence of some tensile and fatigue properties of a dual-phase steel on its microstructure. Metall Mater Trans A 16:1405-1415. doi:10. 1007/BF02658673

40. Sarwar M, Manzoor T, Ahmad E, Hussain N (2007) The role of connectivity of martensite on the tensile properties of a low alloy steel. Mater Des 28:1928-1933. doi:10.1016/j.matdes.2006.05. 010

41. Sarwar M, Ahmad E, Qureshi KA, Manzoor T (2007) Influence of epitaxial ferrite on tensile properties of dual phase steel. Mater Des 28:335-340. doi:10.1016/j.matdes.2005.05.019

42. Azizi-Alizamini H, Militzer M, Poole WJ (2007) A novel technique for developing bimodal grain size distributions in low carbon steels. Scr Mater 57:1065-1068. doi:10.1016/j.scriptamat. 2007.08.035

43. Tasan CC, Hoefnagels JPM, Dekkers ECA, Geers MGD (2012) Multi-axial deformation setup for microscopic testing of sheet metal to fracture. Exp Mech 52:669-678. doi:10.1007/s11340011-9532-x

44. Furnémont Q (2003) The micromechanics of TRIP-assisted multi-phase steels, Ph.D. thesis, Université Catholique de Louvain

45. Lemaitre J, Dufailly J (1987) Damage measurements. J. Eng Fract Mech 28:643-661. doi:10.1016/0013-7944(87)90059-2

46. Tasan CC, Hoefnagels JPM, ten Horn CHLJ, Geers MGD (2009) Experimental analysis of strain path dependent ductile damage 
mechanics and forming limits. Mech Mater 41:1264-1276. doi:10.1016/j.mechmat.2009.08.003

47. Ghadbeigi H, Pinna C, Celotto S, Yates JR (2010) Local plastic strain evolution in a high strength dual-phase steel. Mat Sci Eng A 527:5026-5032. doi:10.1016/j.msea.2010.04.052

48. Hoefnagels JPM, Janssen PJM, de Keijser ThH, Geers MGD (2008) First-order size effects in the mechanics of miniaturized components. In: Dilieu-Barton JM, Lord JD, Greene RJ (eds) Applied mechanics and materials: advanced in experimental mechanics VI, Vol. 13-14. Trans Tech Publications, Switzerland, pp 183-192 